\title{
Giant coronaries: coronary ectasia as an isolated cause of exertional angina and positive stress test
}

\author{
Apurva Vasavada, Navin Agrawal, Pritesh Parekh
}

Department of Cardiology, Care Hospital, Surat, Gujarat, India

\section{Correspondence to} Dr Navin Agrawal, drnavinagrawal@gmail.com

Accepted 9 April 2014

\section{DESCRIPTION}

Coronary artery ectasia (CAE) is characterised by segmental or diffuse dilation of the coronary artery to more than 1.5 times its diameter. ${ }^{1} \mathrm{CAE}$ has been classified by Markis on the basis of the extent of ectasia. ${ }^{2}$ More than half of CAE cases are related to atherosclerotic coronary artery disease. Ectasia is restricted to a single coronary in $75 \%$ cases and is usually segmental. ${ }^{2}$

We present an interesting case of a middle-aged patient with a history of exertional chest pain with a positive exercise ECG stress test. The patient was taken for a diagnostic coronary angiogram which revealed the presence of diffuse ectasia involving all three coronary arteries as well as that of the ramus (figures 1-3 and videos 1-3). The coronaries were dilated to an extent of $7-8 \mathrm{~mm}$ which is a very unusual sight in conventional cardiology practice. Most often dilation is segmental or involves only one of the arteries and the dilation is usually less than what was seen in this case. There was no evidence of any atherosclerosis to account for the anginal symptoms. The patient was decided to be put on conservative medical management including statins and antiplatelets. The symptoms improved to a significant extent with this therapy.

The occurrence of angina due to ectasia has been discussed but its effect on electrocardiogram has not. Coronary ectasia can be a cause of acute thrombus formation which can cause infarction and clogging of microcirculation and slow antegrade flow. This can lead to decreased microcirculation flow gradient which can cause exertional

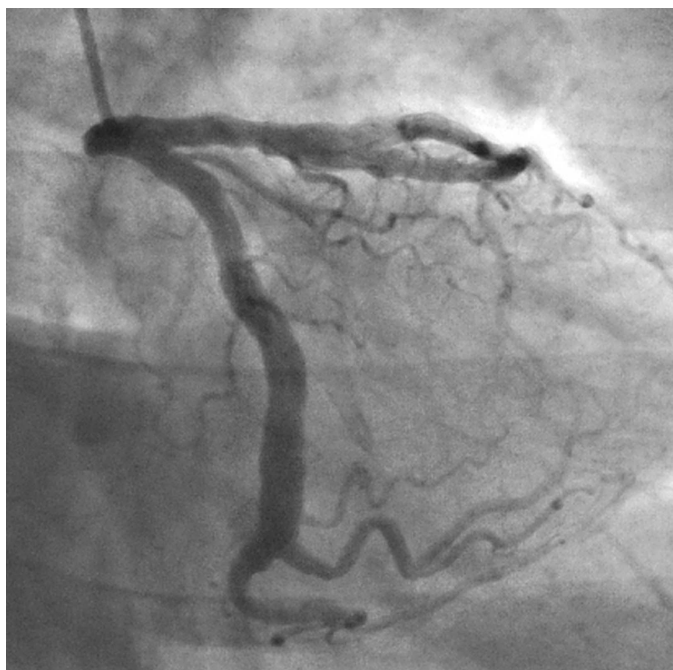

Figure 1 Coronary angiogram in right anterior oblique caudal view showing grossly dilated left circumflex and anterior descending coronary arteries.

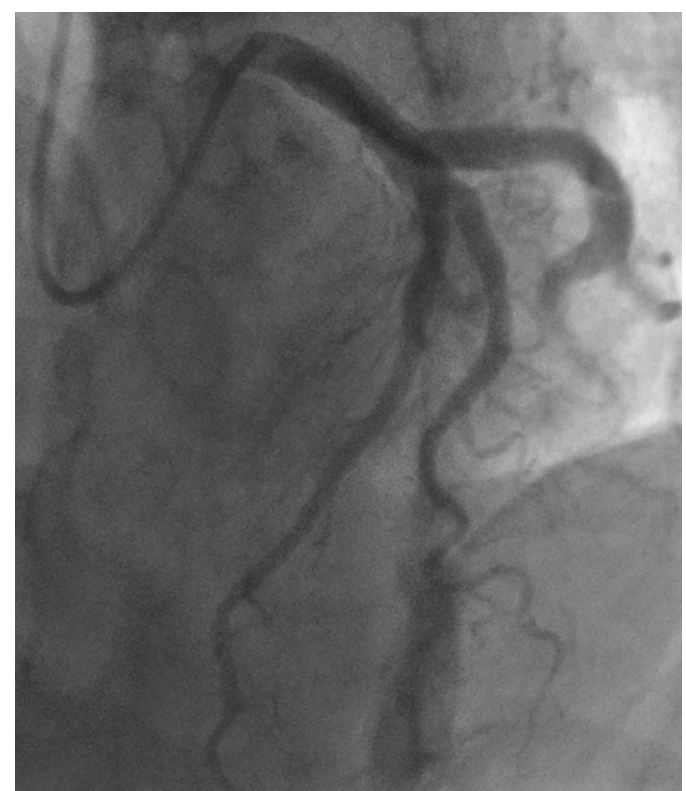

Figure 2 Coronary angiogram in anteroposterior cranial view showing giant left anterior descending, diagonal and left circumflex arteries.

symptoms. ${ }^{1-3}$ These symptoms may not be responsive to conventional antianginal and antiplatelet therapy which has been proved to be effective in case of atherosclerotic coronary artery disease. Diffuse coronary ectasia does not require treatment unless associated with obstructive atherosclerotic lesion or aneurysmal segments which can be

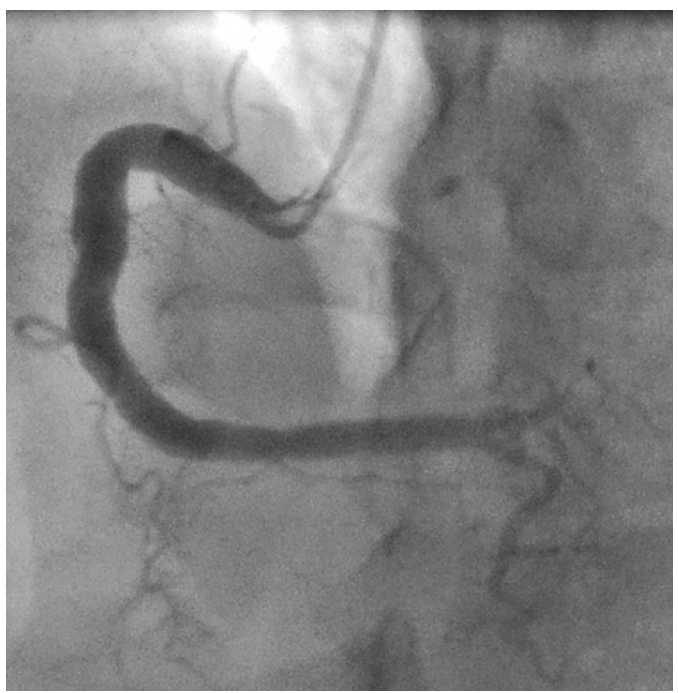

Figure 3 Left anterior oblique view showing grossly ectatic right coronary artery. 


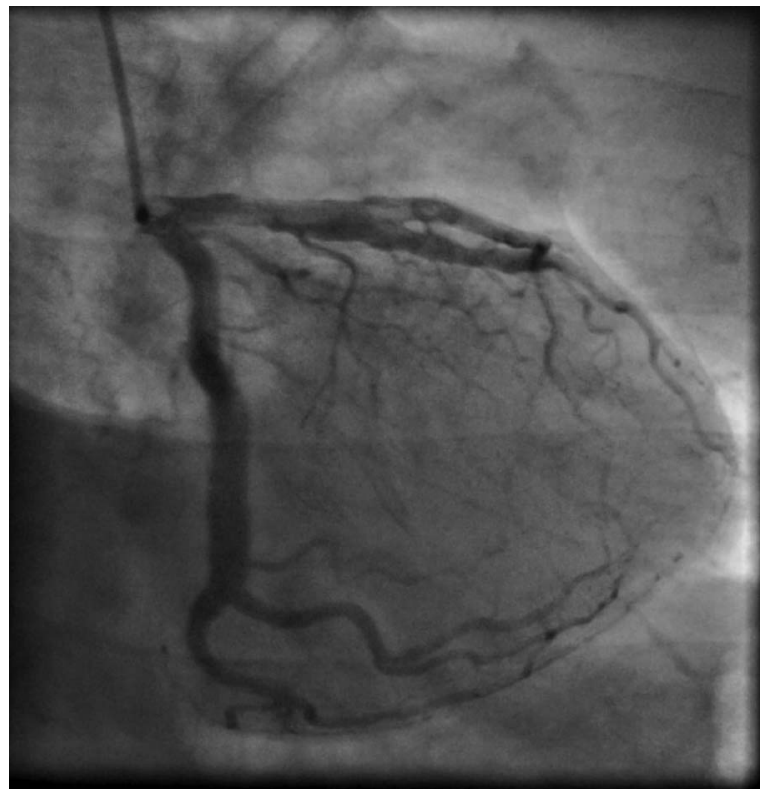

Video 1 Coronary angiogram in right anterior oblique caudal view showing grossly dilated left circumflex and anterior descending coronary arteries.

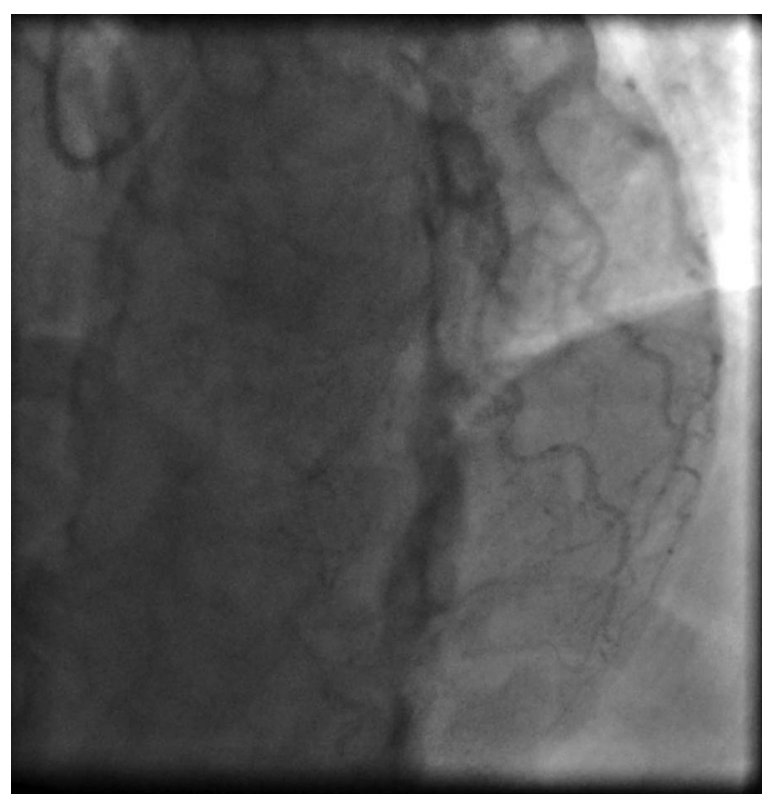

Video 2 Coronary angiogram in anteroposterior cranial view showing giant left anterior descending, diagonal and left circumflex arteries.

surgically corrected or dealt with covered stents. Chronic anticoagulation has been recommended in cases of diffuse ectasia and aneurysms by some studies but does not form a part of the guidelines.

Contributors All the authors have contributed in drafting and finalising the manuscript.

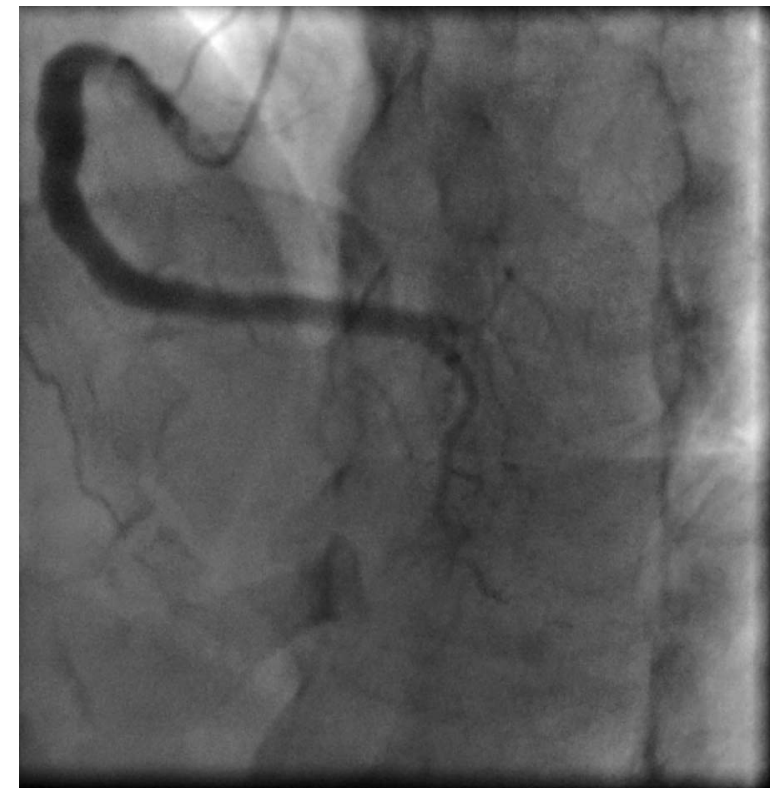

Video 3 Left anterior oblique view showing grossly ectatic right coronary artery.

\section{Learning points}

- Coronary artery ectasia rarely involves all the coronaries and the dilation of all the coronaries to aneurysmal proportions involving the entire length is even rarer as was seen in this case.

- Coronary artery ectasia can be a cause of microcirculatory dysfunction and microcirculation clogging by in situ thrombosis which may be the cause of anginal symptoms in these cases, although the occurrence of a positive ECG in these cases has seldom been discussed. ${ }^{4}$

- Percutaneous interventions in cases of haemodynamically significant atherosclerosis can be challenging in cases with giant coronaries due to difficulty in obtaining hardware and stents to suit the intervention.

Competing interests None.

Patient consent Obtained.

Provenance and peer review Not commissioned; externally peer reviewed.

\section{REFERENCES}

1 Markis JE, Joffe CD, Cohn PF, et al. Clinical significance of coronary arterial ectasia. Am J Cardiol 1976;37:217-22.

2 Papadakis MC, Manginas A, Cotileas $\mathrm{P}$, et al. Documentation of slow coronary flow by the TIMI frame count in patients with coronary ectasia. Am J Cardiol 2001;88:1030-2.

3 Hirapur I, Veeranna R, Agrawal N. Regurgitation of blood flow from the ectatic LAD artery as a cause of angina demonstrated during coronary angiogram. BMJ Case Rep 2014;2014:bcr2013203172.

4 Sayin T, Döven O, Berkalp B, et al. Exercise-induced myocardial ischemia in patients with coronary artery ectasia without obstructive coronary artery disease. Int $J$ Cardiol 2001;78:143-9. 
Copyright 2014 BMJ Publishing Group. All rights reserved. For permission to reuse any of this content visit http://group.bmj.com/group/rights-licensing/permissions.

BMJ Case Report Fellows may re-use this article for personal use and teaching without any further permission.

Become a Fellow of BMJ Case Reports today and you can:

- Submit as many cases as you like

- Enjoy fast sympathetic peer review and rapid publication of accepted articles

- Access all the published articles

- Re-use any of the published material for personal use and teaching without further permission

For information on Institutional Fellowships contact consortiasales@bmjgroup.com

Visit casereports.bmj.com for more articles like this and to become a Fellow 